\title{
Twin Pregnancy discordordant for Downs syndrome: Case Report
}

\author{
Dinu-Florin Albu' ${ }^{1}$, Cristina-Crenguta Albu' ${ }^{2}$, Stefan-Dimitrie Albu ${ }^{3}$ \\ ${ }^{1}$ Dr. Dinu-Florin Albu, MD, Ph.D, Associate Professor, Obstetrics \& Gynecology and Medical Genetics, Expert in \\ Maternal-Fetal Ultrasound and Maternal-Fetal Medicine, ${ }^{2} \mathrm{Dr}$ Cristina-CrengutaAlbu, MD, PhD, Associate \\ Professor,Ophthalmology and Medical Genetics, ${ }^{3}$ Stefan-Dimitrie Albu, Medical Student. All are affiliated with \\ University of Medicine and Pharmacy "Carol Davila", Bucharest, Romania and Alco San Clinic, Maternal-Fetal \\ Medicine Department, Bucharest, Romania
}

Address for Correspondence: Dr. Cristina-Crenguta Albu, E-mail: stevealbu@yahoo.com,27A, Catedrei Street, 1st District, 014162, Bucharest, Romania.

\begin{abstract}
The work presented is a clinical and genetical trial of a couple with a reproductive failure and a family history of chromosomal abnormalities. The most reliable and accurate methods used for antenatal diagnosis of Down syndrome fetuses are highlighted.
\end{abstract}

Key words: Twin Pregnancy, Nuchal Translucency, Robertsonian Translocation, Down Syndrome, Fetal Reduction

\section{Introduction}

The antenatal diagnosis and the abnormal fetal reduction offer the possibility of preventing birth of children having severe birth defects. In particular, in the Down syndrome or Trisomy 21, the antenatal diagnosis requires the simultaneous and combined assessment of multiple markers such as the maternal age, the serum alpha-fetoprotein (AFP), the human chorionic gonadotropin, and the unconjugated serum estriol $[1,2$, 3 , 4, 5], and ultrasound markers (fetal nuchal translucency and morphology) $[6,7,8,9,10]$. The combined use of these tests [11, 12] facilitates the selection of cases that require cytogenetic diagnosis [13]. The cytogenetic investigation is necessary and compulsory [14]. The cytogenetic diagnosis can confirm or rule out, with maximum precision, the existence of chromosome anomalies of number or structure nature in an individual karyotype [15].

The work presented is a clinical and genetical trial of a couple with a reproductive failure and a family history of chromosomal abnormalities. The most reliable and accurate methods used for antenatal diagnosis of Down syndrome fetuses are highlighted.

\section{Case Report}

Manuscript received: $1^{\text {st }}$ June 2015

Reviewed: $14^{\text {th }}$ June 2015

Author Corrected: $24^{\text {th }}$ June 2015

Accepted for Publication: $11^{\text {th }}$ July 2015
A Caucasian woman, aged 28, comes for her first consultation at the Alco San Clinic, Maternal-Fetal Medicine Department, in Bucharest to confirm the pregnancy.

Following the consultation, the woman is diagnosed with twin bichorionic pregnancy, the gestational age being 7 weeks.

The information provided by the patient reveals that she had a previous pregnancy that ended with reproductive failure - antepartum stillbirth in the eighth month with Down syndrome aspect, but uninvestigated cytogenetically. The retrospective diagnosis of the dead fetus was almost impossible to determine.

The presented pregnancy appeared 20 months after the reproductive failure and was not preceded by any medical treatment for this purpose.

The data about the patient's family history shows that her sister has a child with Down syndrome. Based on this history, the patient was asked to bring her husband (aged 30 years old) to the next check up for the direct investigation of the couple.

The members of the couple were living and working in salubrious conditions, not being exposed to a toxic environment. Both genitors are clinically healthy and 
are not consanguineous. The cytogenetic investigation revealed that the husband has normal karyotype 46, XY and the wife has a structural chromosomal abnormality of Robertsonian translocation type 45,XX,-14,-21,+ $\mathrm{t}(14 \mathrm{q}: 21 \mathrm{q})$ - Figure 1.

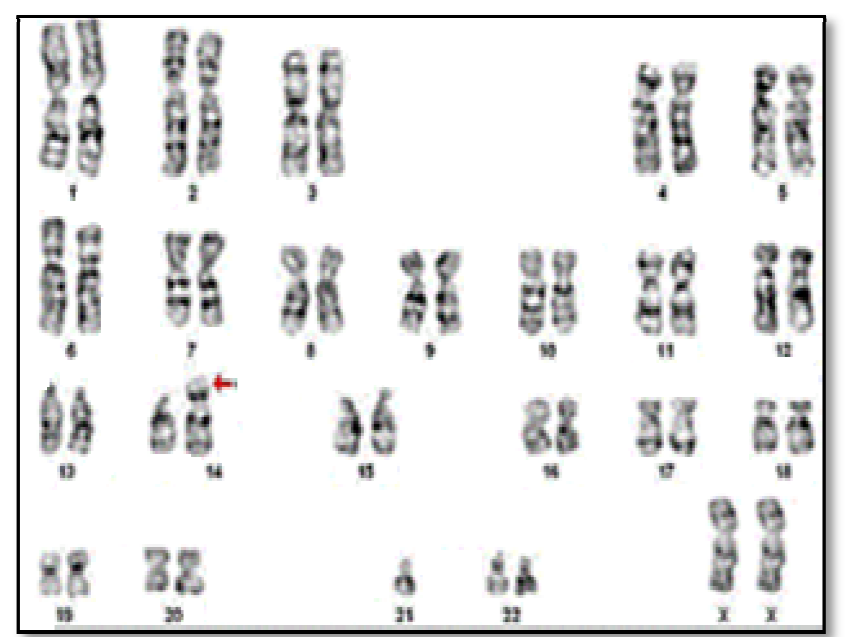

Figure 1: Mother's karyotype, 45,XX,-14,-21,+t(14q: 21q); the arrow indicates a derivative chromosome 14/21
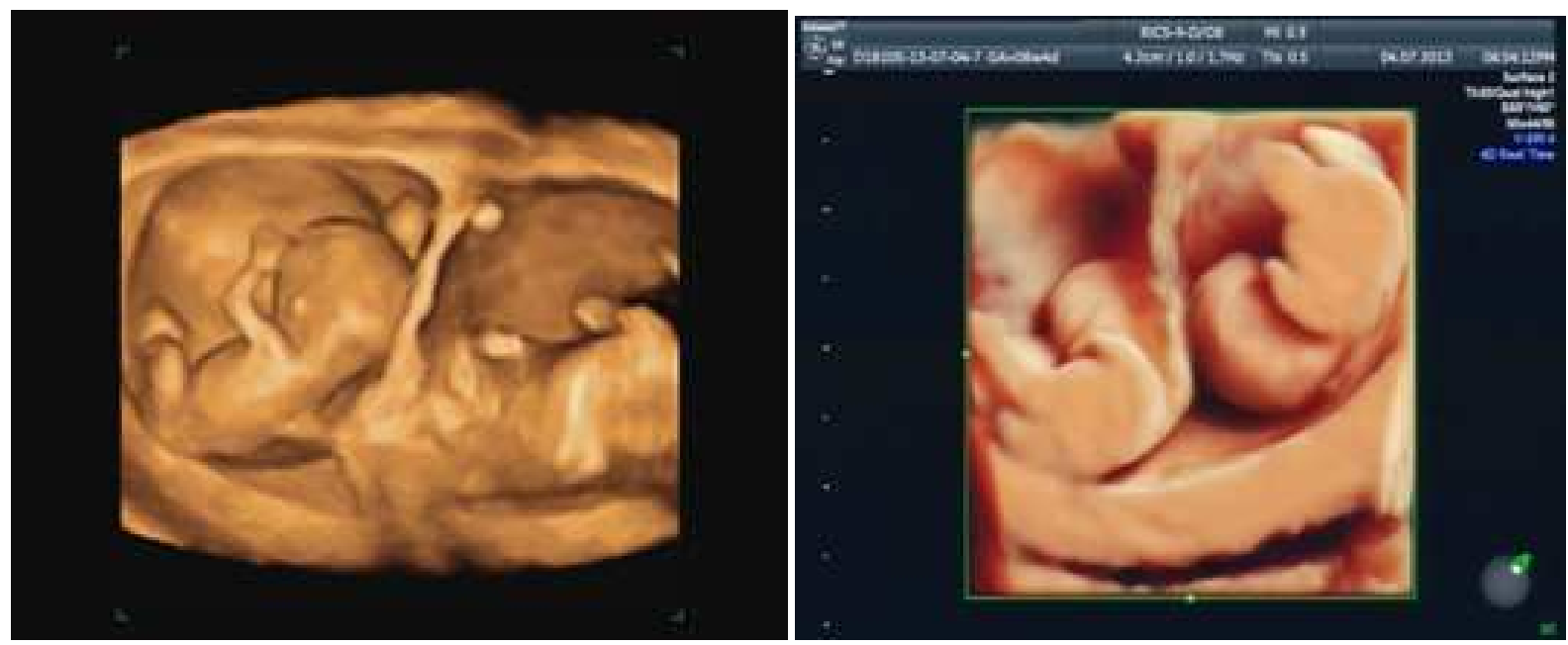

Figure 2 : Twin pregnancy
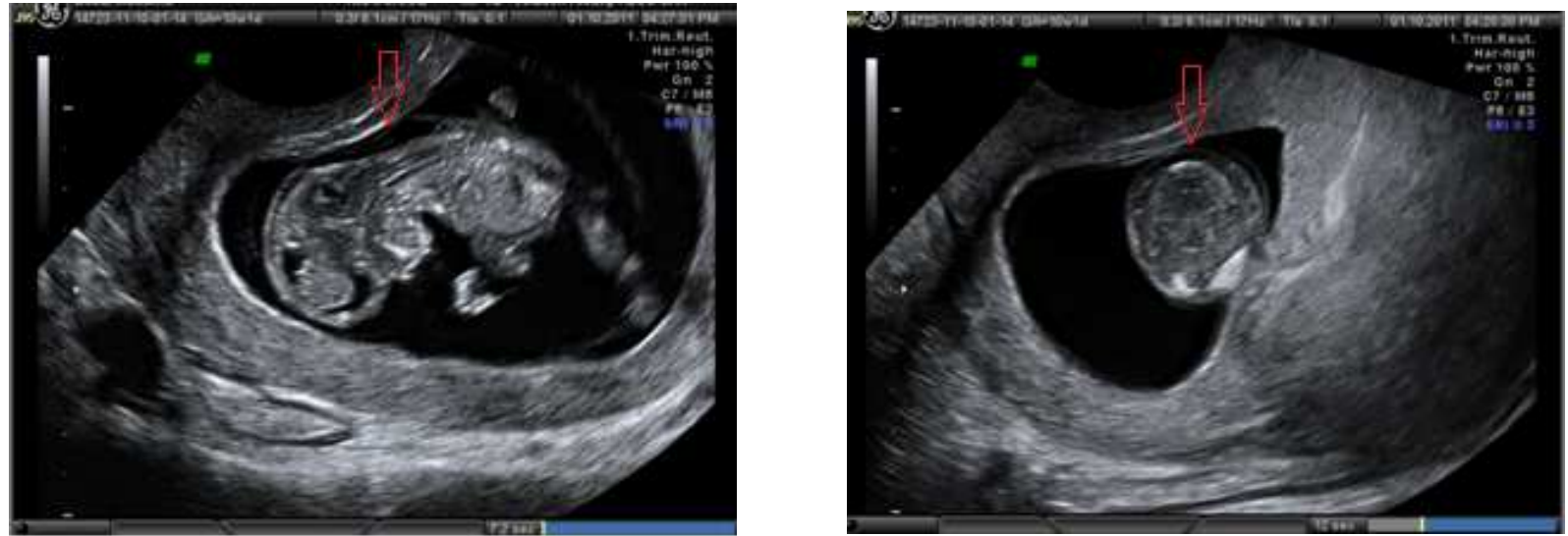

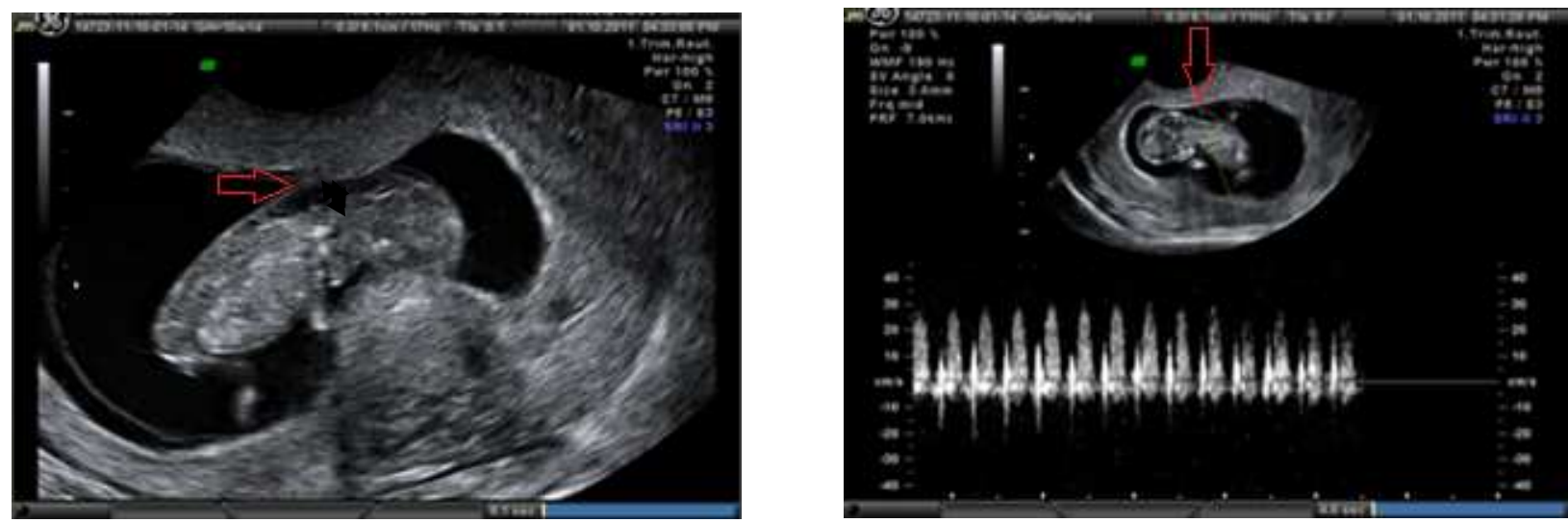

Figure 3: Nuchal translucency

The methods used for monitoring the pregnancy were: first trimester ultrasound (it highlights the nuchal translucency), triple test (AFP, hCG and UE3) in weeks 15-16, amniocentesis in week 16, and the second trimester ultrasound it highlights the fetal dysmorphia.

The investigation results indicated an increased risk for Down syndrome at one of the twins.

-The 12 weeks ultrasound showed in one of the fetuses the nuchal translucency, TN = $3.4 \mathrm{~mm}$ (Figure 3).

-The 15 weeks triple test showed an increased risk for chromosomal abnormalities.

Given the history and the increased risk for developing the Down syndrome in one of the fetuses, the cytogenetic investigation of both fetuses was decided and conducted.

-The amniocentesis was performed with ultrasound guidance in order to remove $20 \mathrm{ml}$ of amniotic fluid.

The cytogenetic analysis of karyotypes and QF-PCR from amniotic fluid revealed that the twins had discordant chromosomal structures: a male fetus, normal 46,XY and a female fetus with trisomy 21 by translocation 46,XX,t(14q:21q) - Figure 4.

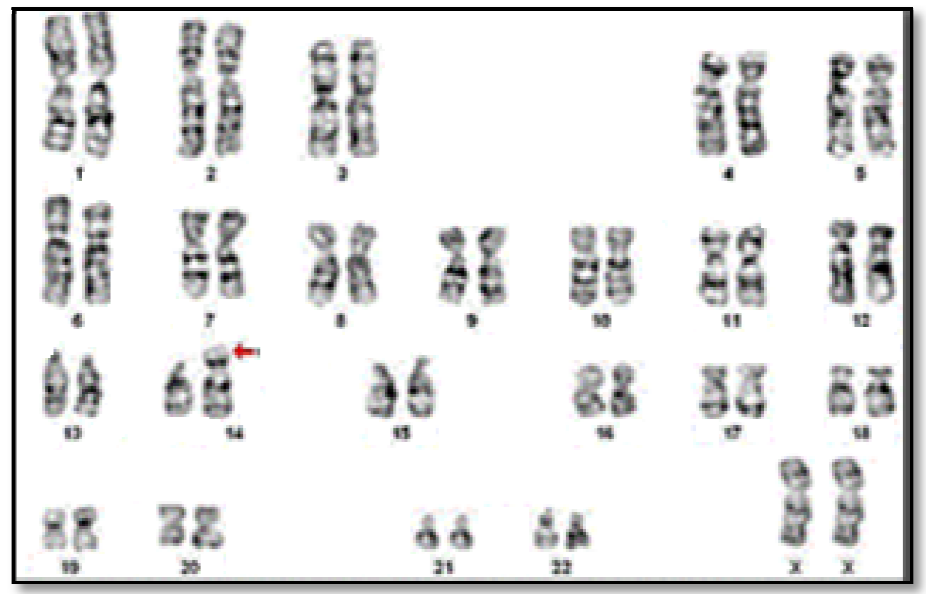

Figure 4: The female fetus karyotype with trisomy 21 by translocation 46,XX,t(14q:21q)

The cytogenetic examination confirmed the suspicion of Down syndrome -suggested by the ultrasound aspect of the fetus and the altered serum results of the triple test. 
With the parents consent, the abnormal fetus reduction is decided, by an intracardiac puncture $\mathrm{KCl}$ solution followed by cardiac saline tamponade.

The normal fetus had a good development. At 39 weeks, the normal fetus was extracted by cesarean birth and it weighed 3,500 gms. At the moment, the mother and her baby are feeling well.

\section{Discussion}

The maternal karyotype analysis revealed the absence of two chromosomes, one from 14 pair and the other of the 21 pair, and the presence of a homologous-free submetacentric chromosome [16]. This is because the mother is the carrier of a balanced chromosomal translocation $[17,18]$.

The translocation involved an acrocentric chromosome of each of the D and G groups of the human karyotype. Thus, a chromosome of the 14 pair and one of the 21 pair spontaneously suffer a rupture each one of its arms; the short arms and small amounts of pericentromeric heterochromatin are lost; the long arms centrically merge and one chromosome appears, a 14/21 derived one [19].

This structural chromosomal abnormality has no phenotypic expression for the bearer, but genetically unbalanced gametes appear in its gametogenesis (with a surplus or deficit of genetic material) and unfavorable consequences for its descendants [3, 17].

The fetus with Down syndrome inherited from the mother the derived 14/21 chromosome and one 21 normal chromosome. In its karyotype a supernumerary chromosome 21 was observed, but not free, but translocated on one of the chromosomes of the 14 pair.

The cytogenetic diagnosis, trisomy 21 by translocation, confirmed the suspicion of Down syndrome.

\section{Conclusions}

- The first term nuchal translucency is a useful marker in early detection of Down syndrome.

- The family history, the maternal serum biochemistry and the maternal and fetal cytogenetic diagnosis facilitated the making of a quick and correct decision -the abnormal fetus reduction.

- The fetal reduction in bichorionic twins is safe and effective for both the mother and the fetus continuing its development.

- Any couple with reproductive failures due to chromosomal defects should benefit from antenatal diagnosis for assessing the risk of recurrence.

\section{References}

1. Albu, D., Albu, C., Severin, E., Toma, A., P01.11: Ultrasound and serum screening at 10-12 weeks of pregnancy with Down syndrome. Ultrasound Obstet Gynecol, 2005, 26: 378. doi: 10.1002/uog.2245.

2. MatiasA,et al .Down syndrome screening in multiple pregnancies. Obstet Gynecol Clin North Am. 2005;32(1):81-96.

3. Cuckle H. Down's syndrome screening in twins.J Med Screen. 1998;5(1):3-4.

4. Palomaki GE, Kloza EM, Haddow JE, Williams J and Knight GJ. Patient and health professional acceptance of integrated serum screening for Down syndrome. Semin Perinatol. 2005 Aug;29(4):247-51.

5. Albu D., Albu C., Severin E., Purcarea R. Twin pregnancy with discordancy for Down syndrome, a case report. European Journal of Human Genetics, Nature Publishing Group. 2005;173.

6. Cicero S, Bindra R, Rembouskos G, Spencer K and Nicolaides KH. Integrated ultrasound and biochemical screening for trisomy 21 using fetal nuchal translucency, absent fetal nasal bone, free beta-hCG and PAPP-A at 11 to 14 weeks. Prenat Diagn. 2003 Apr;23(4):306-10.

7. Nicolaides KH. Nuchal translucency and other firsttrimester sono- graphic markers of chromosomal abnormalities. Am J Obstet Gynecol. 2004 Jul;191(1):45-67.

8. Nicolaides KH, Azar G, Byrne D, Mansur C and Marks K. Fetal nuchal translucency: ultrasound screening for chromosomal defects in first tri- mester of pregnancy. BMJ. 1992 Apr 4;304(6831):867-9.

9. Nicolaides $\mathrm{KH}$, Spencer $\mathrm{K}$, Avgidou $\mathrm{K}$, Faiola S, Falcon O.. Multicenter study of first-trimester screening for trisomy 21 in 75821 pregnancies: results and estimation of the potential impact of individual risk-orientated two-stage first-trimester screening. Ultrasound Obstet Gynecol. 2005 Mar;25(3):221-6. 
10. Malone FD, Ball RH, Nyberg DA, Comstock CH, Saade G, Berkowitz RL, Dugoff L, Craigo SD, Carr SR, Wolfe HM et al. First-trimester nasal bone evaluation for aneuploidy in the general population. Obstet Gynecol. 2004 Dec;104(6):1222-8.

11. Malone FD, Canick JA, Ball RH, Nyberg DA, Comstock CH, Bukowski R, Berkowitz RL, Gross SJ, Dugoff L, Craigo SD et al. First-trimester or secondtrimester screening, or both, for Down's syndrome. N Engl J Med. 2005 Nov 10;353(19):2001-11.

12. Palomaki GE, Kloza EM, Haddow JE, Williams J and Knight GJ. Patient and health professional acceptance of integrated serum screening for Down syndrome. Semin Perinatol. 2005 Aug;29(4):247-51.

13. Jamar M, et al. A low rate of trisomy 21 in twinpregnancies: a cytogenetics retrospective study of 278 cases. Genet Couns. 2003;14(4):395-400.

14. Simpson JL. Choosing the best prenatal screening protocol. N Engl J Med. 2005 Nov 10;353(19):2068-70.
15. Aït Yahya-Graison E, Aubert J, Dauphinot L et al. Classification of human chromosome 21 geneexpression variations in Down syndrome: impacton disease phenotypes. Am J Hum Genet. 2007 Sep;81(3):475-91. Epub 2007 Jul 19.

16. Hassold T., Abruzzo M., Adkins K., Griffin D., Merrill M., Millie E., Saker D., Shen J., Zaragoza M. Human aneuploidy: incidence, origin, and etiology. Environ Mol Mutagen. 1996;28(3):167-75.

17. E. Therman, B. Susman and C. Denniston. The nonrandom participation of human acrocentric chromosomes in Robertsonian translocations. Ann Hum Genet. 1989 Jan;53(Pt 1):49-65..

18. Antonarakis SE, Lewis JG, Adelsberger PA, Petersen MB, Schinzel AA, Binkert F, Schmid W, et al. Parental origin of the extra chromosome in trisomy 21 as indicatedby analysis of DNA polymorphisms. N Engl J Med. 1991 Mar 28;324(13):872-6.

19. Shaffer LG, Lupski JR. Molecular mechanisms for constitutional chromosomal rearrangements in humans. Annu Rev Genet. 2000; 34:297-329.

\section{How to cite this article?}

Dinu-Florin Albu, Cristina-Crenguta Albu, Stefan-Dimitrie Albu. Twin Pregnancy discordordant for Downs syndrome: Case Report. Int J Med Res Rev 2015;3(6):660-664. doi: 10.17511/ijmrr.2015.16.114. 